\title{
PENERAPAN METODE SIMPLE ADDITIVE WEIGHTING DALAM MENENTUKAN POSISI DUDUK PESERTA DIDIK
}

\author{
Moh. Erkamim ${ }^{1)}$, Rendy Bagus Pratama ${ }^{2)}$, Wartono ${ }^{3)}$, Kusrini ${ }^{4)}$ \\ 1,2,3,4) Magister Tenik Informatika, Universitas Amikom Yogyakarta \\ ${ }^{1)}$ moh.erkamim@ students.amikom.ac.id, ${ }^{2)}$ rendybaguspratama@ @mail.com, ${ }^{3)}$ wartana4@ gmail.com. \\ kusrini@amikom.ac.id
}

\begin{abstract}
In learning process, there are several factors influencing the success rate of the learners. One of the supporting factors is a conducive environment which can be created by the ideal sitting position arrangement. Girirejo State Elementary School of Nganjuk still conducted the arrangement randomly resulting uneven seating position and the learning process which do not run optimally. There are students that actually should be sitting in the front and vice versa. To overcome these problems, it takes an election to determine the learners' sitting position in order to get the ideal one. It was done by using a method of Simple Additive Weighting (SAW) with the criteria of value, height, and the use of glasses. The method combined alternative search with seating object in which the seats are sought for the difference of alternative value between the highest and the lowest score of the students that later will be divided by the number of the students. The result is that the highest and the lowest scores will be generated on each seat resulting alternative seats to be occupied by students with the value entered into the value range on the seat. The final result in this research, however, is not yet maximal as there are still vacant seat left. Therefore, it needs to be improved in the mapping of the students' ideal sitting position in the classroom.
\end{abstract}

Keywords: sitting position, saw, ranking.

\section{PENDAHULUAN}

Dalam proses belajar mengajar ada beberapa beberapa faktor yang mempengaruhi tingkat keberhasilan siswa dalam menerima pelajaran. Adapun diantara dari beberapa faktor tersebut antara lain adalah: guru, siswa, metode dan model pembelajaran, mata pelajaran, dan lingkungan kelas. Dari beberapa faktor tersebut perlu seimbang dan ideal. Lingkungan kelas juga menjadi salah satu faktor pendukungnya. Lingkungan kelas yang kondusif dapat dikuasai oleh guru ataupun pengaturan posisi tempat duduk dan teman sebangku siswa. Adapun tujuan dari pengaturan posisi tempat duduk siswa adalah untuk mengoptimalkan kegiatan belajar

Dari hasil observasi pada seorang guru di Sekolah Dasar Negeri Girirejo Nganjuk, peneliti menemukan kurang optimalnya siswa dalam menerima pelajaran. Dampaknya tingkat pemahaman siswa terhadap suatu mata pelajaran menjadi tidak maksimal. Karena kegiatan belajar di kelas dengan posisi tempat duduk yang monoton membuat siswa jenuh. Apabila hal tersebut dibiarkan terus-menerus, maka tujuan pendidikan Bangsa Indonesia tidak bisa tercapai. Hal tersebut akan sangat merugikan beberapa pihak, seperti guru, siswa, orang tua, dan lembaga belajar yang menaunginya. Dari permasalahan tersebut peneliti mencoba menentukan posisi duduk dengan sebuah metode Simple Additive Weighting (SAW) dengan kriteria nilai, tinggi badan, dan penggunaan kacamata, metode tersebut dikobinaskan pencarian alternatif dengan objek tempat duduk dimana tempat duduk dicari alternative selisih nilai antara nilai tertinggi dan nilai terendah siswa, selanjutnya selisih akan dibagi dengan jumlah siswa, nantinya akan dihasilkan nilai tertinggi dan nilai terendah pada setiap kursi, sehingga akan muncul alternative pada kursi 
untuk bisa ditempati oleh siswa dengan bobot nilai yang masuk dalam rentang nilai pada kursi tersebut.

Dalam penelitian ini sudah menghasilkan peringkat siswa untuk mendapatkan kursi, tetapi belum maksimal sesuai dengan yang direncanakan dikarenakan ketika objeknya digantikan dengan tempat duduk hasilmya masih ada kursi yang masih kosong tidak terisi oleh siswa, sehingga perlu dilakukan perbaikan kedepannya untuk bisa mencari alternatif setiap kursi agar terisi oleh semua siswa dan dapat menghasilkan posisi alternatif sehingga dapat membatu guru dalam memetakan posisi duduk siswanya yang ideal di dalam kelas.

\section{TINJAUAN PUSTAKA}

\subsection{Rotasi Posisi Duduk Siswa}

Tempat duduk dapat mempengaruhi siswa dalam belajar. Dalam mengatur tempat duduk sebernarnya akan berhubungan dengan permasalahan siswa sebagai individu dengan perbedaan pada aspek biologis, intelektual, dan psikologis (Djamarah dan Aswan, 2013).

Pengaturan tempat duduk siswa dapat mempengaruhi peserta didik dalam mencapai keberhasilannya. Perubahan formasi tempat duduk memiliki banyak manfaat yaitu menghindarikejenuhan peserta didik, menjadikan fokus belajar tetap terjaga, meningkatkan konsentrasi belajar, memudahkan guru maupun siswa untuk bergerak dan berinteraksi pada saat kegiatan - belajar mengajar berlangsung (Djamarah dan Aswan, 2013).

Menurut (Ariyanto, 2013) Penataan rotasi duduk adalah salah satu upaya yang dilakukan oleh guru dalam mengelola kelas. Karena pengelolaan kelas yang efektif akan menentukan hasil pembelajaran yang dicapai. Dengan penataan tempat duduk yang baik maka diharapkan akan menciptakan kondisi belajar yang kondusif, dan juga menyenangkan bagi siswa (Djamarah dan Aswan, 2013).

Posisi tempat duduk siswa memang mempunyai pengaruh terhadap prestasinya di kelas. Dimana siswa yang duduk di bangku depan mau tidak mau harus memperhatikan guru yang sedang mengajar. Sehingga secara tidak langsung siswa tersebut akan mudah menyerap materi. Berbeda dengan siswa yang duduk di belakang, mereka memiliki kesempatan lebih banyak untuk tidak memperhatikan guru dalam proses pembelajaran (Djamarah dan Aswan, 2013).

\subsection{Metode Sistem Additive Weighting (SAW)}

Konsep dasar metode SAW adalah mencari penjumlahan terbobot dari rating kinerja pada setiap alternatif pada semua atribut. Metode SAW membutuhkan proses normalisasi matriks keputusan (X) ke suatu skala yang dapat diperbandingkan dengan semua rating alternatif yang ada (Kusumadewi, dkk, 2006).

Dalam penelitihan ini metode SAW (Simple Additive Weighting) Adapun langkahlangkahnya adalah :

1. Menentukan kriteria-kriteria yang akan dijadikan acuan dalam pengambilan keputusan, yaitu Ci.

2. Menentukan rating kecocokan setiap alternatif pada setiap kriteria.

3. Membuat matriks keputusan berdasarkan kriteria(Ci), kemudian melakukan normalisasi matriks berdasarkan persamaan yang disesuaikan dengan jenis atribut (atribut keuntungan ataupun atribut biaya) sehingga diperoleh matriks ternormalisasi R.

4. Hasil akhir diperoleh dari proses perankingan yaitu penjumlahan dari perkalian matriks ternormalisasi $\mathrm{R}$ dengan vektor bobot sehingga diperoleh nilai terbesar yang dipilih sebagai alternatif terbaik (Ai) sebagai solusi (Kusumadewi, dkk, 2006). Formula untuk melakukan normalisasi fungsi seperti pada rumus (1) 


$$
r_{i j}=\left\{\begin{array}{cl}
\frac{x_{i j}}{\operatorname{maxx}_{i j}} & \text { Jika j adalah atribut } \\
\frac{i}{\operatorname{minx}_{i j}} & \text { keuntungan (benefit) } \\
\frac{\mathrm{i}}{\mathrm{x}_{\mathrm{ij}}} & \text { Jika } \mathrm{j} \text { adalah atribut biaya } \\
\text { (cost) }
\end{array}\right.
$$

Dimana :

$\mathrm{r}_{\mathrm{ij}} \quad=$ Rating kinerja ternormalisasi

$\operatorname{Max}_{\mathrm{ij}}=$ Nilai maksimum dari setiap baris dan kolom

$\operatorname{Min}_{\mathrm{ij}}=$ Nilai minimum dari setiap baris dan kolom

$\mathrm{X}_{\mathrm{ij}} \quad=$ Baris dan kolom dari matriks

Dengan $\mathrm{r}_{\mathrm{ij}}$ adalah rating kinerja ternormalisasi

dari alternatif $A_{i}$ pada atribut $C_{j} ; i=1,2, \ldots$ m dan $j=1,2, \ldots, n$.

Nilai preferensi untuk setiap alternatif $\left(\mathrm{V}_{\mathrm{i}}\right)$ diberikan seperti pada rumus $(2)$

Dimana :

$$
\begin{array}{ll}
\mathrm{V}_{\mathrm{i}}= & \sum_{j=1}^{n} W_{j} r_{i j} \\
\mathrm{~V}_{\mathrm{i}} & =\text { Nilai akhir dari alternative } \\
\mathrm{w}_{\mathrm{j}} & =\text { Bobot yang telah ditentukan } \\
\mathrm{r}_{\mathrm{ij}} & =\text { Normalisasi matriks }
\end{array}
$$

Nilai $V_{i}$ yang lebih besar mengindikasikan bahwa alternatif $A_{i}$ lebih terpilih (Kusumadewi, dkk, 2006).

\subsection{Sistem Pendukung Keputusan}

Decision Support System (DSS) biasanya dibangun untuk mendukung solusi atas suatu masalah atau untuk mengevaluasi suatu peluang. DSS yang seperti itu disebut aplikasi DSS. Aplikasi DSS digunakan dalam pengambilan keputusan. Aplikasi DSS menggunakan CBIS (Computer Based Information System) yang fleksibel, interaktif, dan dapat diadaptasi, yang dikembangkan untuk mendukung solusi atas masalah manajemen spesifik yang tidak terstruktur. Aplikasi DSS menggunakan data, memberikan antarmuka pengguna yang mudah, dan dapat menggabungkan pemikiran pengambilan keputusan. DSS lebih ditujukan untuk mendukung keputusan manajemen dalam melakukan pekerjaan yang bersifat analitis dalam situasi yang kurang terstruktur dan dengan kriteria yang kurang jelas. DSS tidak dimaksudkan untuk mengotomatisasikan pengambilan keputusan, tetapi memberikan perangkat interaktif yang memungkinkan pengambilan keputusan untuk melakukan berbagai anallisis menggunakan model-model yang tersedia (Kusrini, 2007).

\section{METODE PENELITIAN}

Dalam penelitian ini digunakan metode action research, pengertian dari metode action research adalah kegiatan atau tindakan perbaikan sesuatu yang perencanaan, pelaksanaan dan evaluasinya dikerjakan secara sistimatis sehingga validitas dan reliabilitasnya mencapai tingkatan riset (Gunawan, 2007).

Action research juga merupakan proses yang mencakup siklus aksi, yang berdasarkan pada refleksi, umpan balik (feedback), bukti(evidence), dan evaluasi atas aksi sebelumnya dan situasi sekarang. Penelitian tindakan bertujuan untuk memperoleh pengetahuan untuk 
situasi atau sasaran khusus dari pada pengetahuan yang secara ilmiah tergeneralisasi (Madya, 2006). Alur action research ini ditunjukkan pada Gambar 1.

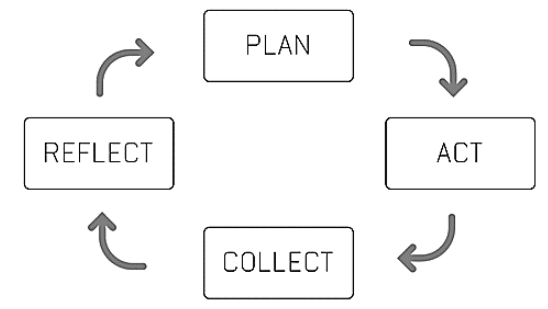

Gambar 1. Alur action research

a) Membuat rencana tindakan (action planning)

Peneliti dan bersama guru memahami permasalahaan pokok masalah yang ada kemudian dilanjutkan dengan menyusun rencana tindakan yang tepat untuk menyelesaikan masalah penentuan posisi berdasarkan kriteria kriteria yang ditentukan.

b) Melakukan tindakan (action taking)

Peneliti dan partisipan bersama-sama mengimplementasikan rencana penentuan bobot kriteria untuk selanjutnya dilakukan perhitungan menggunakan metode yang akan digunakan. Selanjutnya dilanjutkan dengan mengadakan ujicoba awal melihat kondisi didalam kelas untuk melihat perbandingan kesesuaian dengan posisi yang sebelumnya.

c) Melakukan Evaluasi (evaluating)

Setelah masa implementasi (action taking) dianggap cukup kemudian peneliti bersama guru melaksanakan evaluasi hasil dari prototype yang sudah dibuat tadi, dalam tahap ini dilihat bagaimana penerimaan pengguna yakni guru terhadap prototype.

d) Melakukan Reflect (Reflecting)

Gambaran hasil prototype yang sudah dilakukan evaluasi dan penerimaan pengguna terhadap hasil evaluasi dan dilakukan perbaikan perbaikan terhadap proses dalam penentuan posisi tempat duduk.

\section{HASIL DAN PEMBAHASAN}

Dalam pengujian ini menggunakan algoritma Simple Additive Weighting (SAW) sebagai penentuan alternatif dengan memakai 3 kriteria yaitu nilai, tinggi badan dan penggunaan kacamata. Masing-masing kriteria memiliki konversi kriteria, Seperti kacamata memiliki konversi kriteria memakai dan tidak memakai. Begitu pula dengan nilai, dan tinggi badan,

Dalam skenario pengujian user akan melakukan konversi kriteria nilai, tinggi badan dan berat badan dengan cara mengentri nilai secara acak ke dalam sistem. Kemudian sistem akan secara otomatis melakukan konversi yang telah ditentukan. Setelah konversi dari setiap kriteria selesai sistem akan melakukan proses perhitungan.

Alternatif yang digunakan adalah seluruh siswa dalam suatu kelas, namun dalam pengujian ini digunakan sampel sebanyak 7 dari 22 data yang diperoleh. Sistem akan memproses alternatif dimana alternatif rangking 1 berhak mendapatkan posisi duduk dekat dengan letak posisi duduk guru dilanjutkan dengan rangking 2 dan seterusnya.

Pada setiap alternatif akan memiliki 3 kriteria yang telah dipaparkan di atas. Adapun kriteria yang digunakan memiliki bobot disajikan dalam Tabel 1. 
Tabel 1. Kriteria dan Bobot

\begin{tabular}{|c|l|c|}
\hline No & \multicolumn{1}{|c|}{ Kriteria } & Bobot \\
\hline 1 & Penggunaan kacamata $(\mathrm{C} 1)$ & 4 \\
\hline 2 & Tinggi badan(C2) & 3 \\
\hline 3 & Nilai $(\mathrm{C} 3)$ & 2 \\
\hline
\end{tabular}

Setiap kriteria memiliki opsi dan nilai atau bisa disebut juga konversi kriteria pada Tabel 2. Tabel 2. Konversi Kriteria

\begin{tabular}{|c|c|c|c|}
\hline No & Kriteria & Konversi & Nilai \\
\hline \multirow{2}{*}{1} & \multirow{2}{*}{ Kacamata } & Memakai & 2 \\
\hline & & Tidak memakai & 1 \\
\hline \multirow{4}{*}{2} & \multirow{4}{*}{ Tinggi badan } & $170-175$ & 1 \\
\hline & & $166-170$ & 2 \\
\hline & & $161-165$ & 3 \\
\hline & & $155-160$ & 4 \\
\hline \multirow{10}{*}{3} & \multirow{10}{*}{ Nilai siswa } & $96-100$ & 1 \\
\hline & & $91-95$ & 1.33 \\
\hline & & $86-90$ & 1.66 \\
\hline & & $81-85$ & 2 \\
\hline & & $76-80$ & 2.33 \\
\hline & & $71-75$ & 2.66 \\
\hline & & $66-70$ & 3 \\
\hline & & $61-65$ & 3.33 \\
\hline & & $56-60$ & 3.66 \\
\hline & & $\leq 55$ & 4 \\
\hline
\end{tabular}

Dalam simulasi ini diambil semua sampel sebagai bahan pengujian yang disajikan dalam Tabel 3.

Tabel 3 Pengujian

\begin{tabular}{|c|l|c|c|c|}
\hline \multirow{2}{*}{ No } & \multirow{2}{*}{ Alternatif } & \multicolumn{3}{|c|}{ Kriteria } \\
\cline { 3 - 5 } & & $(\mathbf{C 1})$ & $(\mathbf{C 2})$ & $\mathbf{( C 3 )}$ \\
\hline 1 & ANDI & Ya & 173 & 62 \\
\hline 2 & BAGUS & Tidak & 168 & 71 \\
\hline 3 & CANDY & Tidak & 165 & 95 \\
\hline 4 & DIDOT & Ya & 170 & 60 \\
\hline 5 & EKA & Tidak & 155 & 95 \\
\hline 6 & FITRI & Ya & 160 & 90 \\
\hline 7 & GALUH & Ya & 163 & 77 \\
\hline
\end{tabular}

Pada data diatas akan dikonversikan dengan nilai yang ditentukan, selanjutnya nilai tersebut dijadikan nilai matrik $\mathrm{X}$ yang disajikan pada Tabel 4 . 
Tabel 4. Nilai Matrik

\begin{tabular}{|c|l|c|c|c|}
\hline \multirow{2}{*}{ No } & \multirow{2}{*}{ Alternatif } & \multicolumn{3}{|c|}{ Kriteria } \\
\cline { 3 - 5 } & & $(\mathbf{C 1})$ & $(\mathbf{C 2})$ & $(\mathbf{C 3})$ \\
\hline 1 & ANDI & 2 & 1 & 3.33 \\
\hline 2 & BAGUS & 1 & 2 & 2.66 \\
\hline 3 & CANDY & 1 & 3 & 1.33 \\
\hline 4 & DIDOT & 2 & 1 & 3.66 \\
\hline 5 & EKA & 1 & 4 & 1.33 \\
\hline 6 & FITRI & 2 & 4 & 1.66 \\
\hline 7 & GALUH & 2 & 3 & 2.33 \\
\hline
\end{tabular}

Selanjutnya melakukan normalisasi menggunakan kriteria benefit sehingga dicari nilai max dari semua data kriteria dari Tabel matrik $X$. dari hasil mencari nilai max dari masing-masing kriteria didapatkan pembaginya : 4, 3, 2. Berikut perhitungan normalisasi pada Tabel 5.

Tabel 5 Normalisasi

\begin{tabular}{|c|l|c|c|c|}
\hline \multirow{2}{*}{ No } & \multirow{2}{*}{ Alternatif } & \multicolumn{3}{|c|}{ Kriteria } \\
\cline { 3 - 5 } & & $\mathbf{( C 1 )}$ & $\mathbf{( C 2 )}$ & $\mathbf{( C 3 )}$ \\
\hline 1 & ANDI & $2 / 4=0.5$ & $1 / 3=0.33$ & $3,33 / 2=1,66$ \\
\hline 2 & BAGUS & $1 / 4=0.25$ & $2 / 3=0.67$ & $2,66 / 2=1,33$ \\
\hline 3 & CANDY & $1 / 4=0.25$ & $3 / 3=1$ & $1,33 / 2=0.66$ \\
\hline 4 & DIDOT & $2 / 4=0.5$ & $1 / 3=0.33$ & $3,66 / 2=1,83$ \\
\hline 5 & EKA & $1 / 4=0.25$ & $4 / 3=1,33$ & $1,33 / 2=0,66$ \\
\hline 6 & FITRI & $2 / 4=0.5$ & $4 / 3=1,33$ & $1,66 / 2=0,83$ \\
\hline 7 & GALUH & $2 / 4=0.5$ & $3 / 3=1$ & $2.33 / 2=1,16$ \\
\hline
\end{tabular}

Setelah didapatkan nilai normalisasi selanjutnya mencari nilai $\mathrm{V}$ untuk mendapatkan hasil akhir yang nantinya digunakan sebagai perangkingan dengan cara menjumlahkan dari perkalian bobot kriteria dengan matrik normalisasi seperti pada Tabel 6 .

Tabel 6 Pengujian Nilai V

\begin{tabular}{|c|l|r|r|}
\hline No & \multicolumn{1}{|c|}{ Alternatif } & \multicolumn{1}{c|}{ Perhitungan } & \multicolumn{1}{c|}{ Nilai V } \\
\hline 1 & ANDI & $(0.5 * 4)+(0.33 * 3)+(1.66 * 2)$ & 6.33 \\
\hline 2 & BAGUS & $(0.25 * 4)+(0.67 * 3)+(1.33 * 2)$ & 5.66 \\
\hline 3 & CANDY & $(0.25 * 4)+(1 * 3)+(0.66 * 2)$ & 5.33 \\
\hline 4 & DIDOT & $(0.5 * 4)+(0.33 * 3)+(1.83 * 2)$ & 6.66 \\
\hline 5 & EKA & $(0.5 * 4)+(1.33 * 3)+(0.83 * 2)$ & 6.33 \\
\hline 6 & FITRI & $(0.5 * 4)+(1 * 3)+(1.16 * 2)$ & 7.66 \\
\hline 7 & GALUH & & 7.33 \\
\hline
\end{tabular}

Hasil rangking didapatkan dari pengurutan nilai V dari besar ke kecil. Perangkingan ini dijadikan acuan untuk menentukan posisi duduk yang ada dikelas. Alternatif yang memiliki tinggi akan mendapatkan posisi didepan dan sebaliknya, seperti Tabel 7. 
Tabel 7 Rangking

\begin{tabular}{|c|l|c|}
\hline Rangking & \multicolumn{1}{|c|}{ Alternatif } & Nilai V \\
\hline 1 & FITRI & 7.66 \\
\hline 2 & GALUH & 7.33 \\
\hline 3 & DIDOT & 6.66 \\
\hline 4 & EKA & 6.33 \\
\hline 5 & ANDI & 6.33 \\
\hline 6 & BAGUS & 5.66 \\
\hline 7 & CANDY & 5.33 \\
\hline
\end{tabular}

Adapun pengaturan posisi duduk peringkat pertama akan mendapatkan posisi duduk paling depan berhadapan dengan posisi duduk guru dan dilanjutkan ke samping kanan sampai urutan rangking 6 . Rangking 7 berada di belakang rangking 1 dan seterusnya mengikuti pola didepannya. Posisi meja kursi dikelas ditunjukan pada Gambar 2.

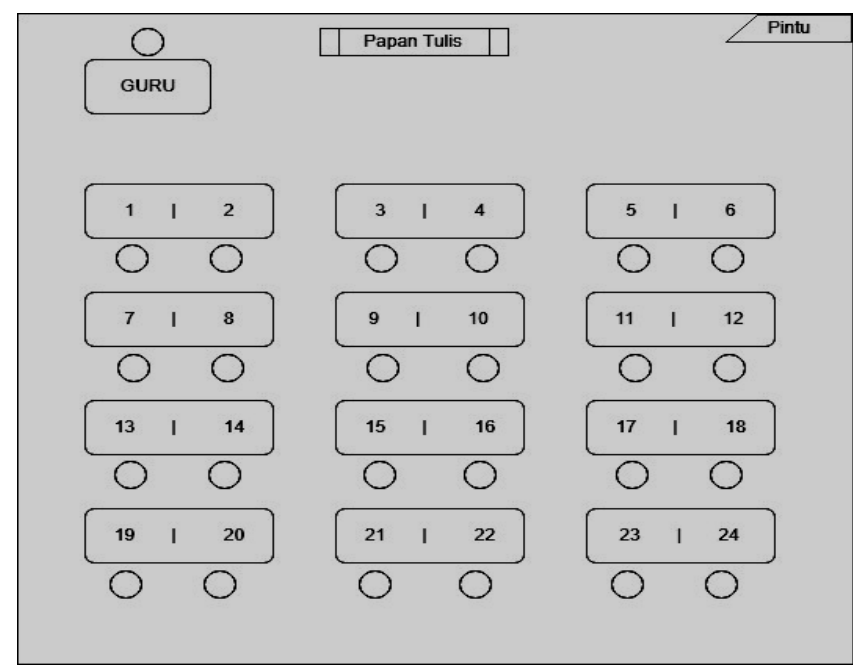

Gambar 2. Gambar posisi meja kursi dikelas

Setelah dilakukan perangkingan dengan Simple Additive Weighting (SAW) dan ditemukan hasil peringkat posisi duduk siswa, selain itu penelitian ini mencoba untuk mencari alternative untuk mengetahui bahwa tempat duduk tersebut bisa digunakan oleh siapa saja, yakni dengan mencoba mencari bilai rangking tertinggi dengan di kurangi nilai teresndah dalam rangking selanjutnya selisih antara nilai tertinggi dan terendah dibagi sejumlah kursi tersebut. Hasil dari pencarian range untuk mengetahui alternatif seperti Tabel 8 berikut ini.

Tabel 8 Range Alternative

\begin{tabular}{|r|l|r|r|}
\hline \multicolumn{1}{|l|}{ No } & Kursi & Range max & Range min \\
\hline 1 & Kursi 1 & 8.33 & 8.15 \\
\hline 2 & Kursi 2 & 8.15 & 7.96 \\
\hline 3 & Kursi 3 & 7.96 & 7.78 \\
\hline 4 & Kursi 4 & 7.78 & 7.60 \\
\hline 5 & Kursi 5 & 7.60 & 7.41 \\
\hline 6 & Kursi 6 & 7.41 & 7.23 \\
\hline 7 & Kursi 7 & 7.23 & 7.05 \\
\hline
\end{tabular}


Implementasi Algoritma Simple Additive Weighting (SAW) ke dalam prototype dari proses penghitungan manual yang selanjutnya implementasikan ke dalam sistem untuk mengetahui kesesuain hasil penghitungan manual dengan prototype yang buat untuk mengetahui peringkat siswa yang bisa menduduki kursi sesuai dengan nilai kriteria. Pertama hasil inputan nilai siswa oleh guru ditampilkan pada Gambar 3.

\begin{tabular}{|c|c|c|c|c|c|c|c|}
\hline 20 Dashboard & \multicolumn{6}{|c|}{ న Home > Dashboard } & \\
\hline E6 Proses Perhitungan & \multirow{2}{*}{\multicolumn{7}{|c|}{ Proses Penghitungan Kriteria }} \\
\hline [8 Hasil Perhitungan & & & & & & & \\
\hline [C Posisi Duduk & \multicolumn{6}{|c|}{$\checkmark$ Selamat datang Sistem Pendukung Keputusan (SPK) Penentuan Posisi Duduk Siswa Sekolah Dasar Negeri (SDN) Girirejo Nganjuk } & $x$ \\
\hline (1) & & & & & & & \\
\hline & \multicolumn{7}{|c|}{ Proses Pengujian Data Siswa } \\
\hline & \multicolumn{7}{|c|}{ Proses Pengujian } \\
\hline & No & Nama & Penggunaan Kacamata & Tinggi Badan & Nilai Sekolah & & \\
\hline & 1 & andi & 2 & $173 \mathrm{~cm}$ & 62 & Q 而 & \\
\hline & 2 & bagus & 1 & $168 \mathrm{~cm}$ & 71 & $Q$ & \\
\hline & 3 & candy & 1 & $165 \mathrm{~cm}$ & 95 & $Q$ & \\
\hline & 4 & didot & 2 & $170 \mathrm{~cm}$ & 60 & $Q$ & \\
\hline & 5 & eka & 1 & $155 \mathrm{~cm}$ & 95 & $Q$ & \\
\hline & 6 & fitri & 2 & $160 \mathrm{~cm}$ & 90 & $Q>$ 而 & \\
\hline & 7 & galuh & 2 & $163 \mathrm{~cm}$ & 77 & $Q$ & \\
\hline & 8 & heni & 1 & $167 \mathrm{~cm}$ & 73 & $Q$ & \\
\hline & 9 & indah & 2 & $168 \mathrm{~cm}$ & 60 & $Q$ & \\
\hline & 10 & jebri & 1 & $165 \mathrm{~cm}$ & 85 & $Q$ & \\
\hline & 11 & karin & 2 & $162 \mathrm{~cm}$ & 95 & $Q<$ 而 & \\
\hline & 12 & layli & 1 & $158 \mathrm{~cm}$ & 61 & $Q$ & \\
\hline & 13 & maya & 1 & $168 \mathrm{~cm}$ & 67 & Q 囬 & \\
\hline & 14 & nisa & 2 & $171 \mathrm{~cm}$ & 60 & $Q$ & \\
\hline & 15 & oni & 2 & $173 \mathrm{~cm}$ & 76 & $Q$ & \\
\hline & 16 & pepi & 2 & $159 \mathrm{~cm}$ & 83 & $Q$ & \\
\hline & 17 & ratna & 1 & $168 \mathrm{~cm}$ & 88 & $Q$ & \\
\hline & 18 & sukma & 2 & $155 \mathrm{~cm}$ & 95 & $Q$ & \\
\hline & 19 & tina & 1 & $165 \mathrm{~cm}$ & 82 & $Q$ & \\
\hline & 20 & ve & 1 & $152 \mathrm{~cm}$ & 73 & $Q$ & \\
\hline
\end{tabular}

Gambar 3. prototype input nilai kriteria data siswa

Nilai pada Tabel diatas didapatkan dari entri data nilai masing - masing siswa. Setelah mendapatkan nilai siswa yang akan diolah, ditunjukkan pada Gambar 4 
Nilai Matrik

\begin{tabular}{|c|c|c|c|c|c|}
\hline \multicolumn{6}{|c|}{ Penghitungan Nilai Matrik } \\
\hline No & Nama & Penggunaan Kacamata & Tinggi Badan & Nilai Sekolah & \\
\hline 1 & andi & 2 & 1.00 & 3.33 & $Q>$ 角 \\
\hline 2 & bagus & 1 & 2.00 & 2.66 & $Q>$ 每 \\
\hline 3 & candy & 1 & 3.00 & 1.33 & Q 自 \\
\hline 4 & didot & 2 & 1.00 & 3.66 & $Q>$ 酌 \\
\hline 5 & eka & 1 & 4.00 & 1.33 & Q \\
\hline 6 & fitri & 2 & 4.00 & 1.66 & $Q$ 角 \\
\hline 7 & galuh & 2 & 3.00 & 2.33 & Q \\
\hline 8 & heni & 1 & 2.00 & 2.66 & Q \\
\hline 9 & indah & 2 & 2.00 & 3.66 & Q $>$ 苗 \\
\hline 10 & jebri & 1 & 3.00 & 2.00 & Q>面 \\
\hline 11 & karin & 2 & 3.00 & 1.33 & Q 角 \\
\hline 12 & |ayli & 1 & 4.00 & 3.33 & $Q>$ 角 \\
\hline 13 & maya & 1 & 2.00 & 3.00 & Q $>$ 画 \\
\hline 14 & nisa & 2 & 1.00 & 3.66 & Q \\
\hline 15 & oni & 2 & 1.00 & 2.33 & Q \\
\hline 16 & pepi & 2 & 4.00 & 2.00 & Q 而 \\
\hline 17 & ratna & 1 & 2.00 & 1.66 & $Q>$ 囬 \\
\hline 18 & sukma & 2 & 4.00 & 1.33 & Q 苗 \\
\hline 19 & tina & 1 & 3.00 & 2.00 & Q \\
\hline 20 & ve & 1 & 4.00 & 2.66 & Q \\
\hline
\end{tabular}

Gambar 4. prototype nilai matrik

Penghitungan nilai $\mathrm{V}$ dilakuka setelah pencocokan nilai yang ada dengan konversi kriteria didapatkan matrik X perbandingan. Selanjutnya dilakukan normalisasi metode SAW pada Tabel 5. Dimana perilaku, nilai, tinggi badan dan penggunaan kacamata termasuk kriteria benefit, penghitungan nilai $\mathrm{V}$ ditunjukkan pada Gambar 5

Proses Pengujian Nilai $\mathrm{V}$

\begin{tabular}{|c|c|c|c|}
\hline \multicolumn{4}{|c|}{ Pengujian Nilaiv } \\
\hline No & Alternatif Nama & Nilai V & \\
\hline 1 & andi & 6.33 & Q 圆 \\
\hline 2 & bagus & 5.66 & Q 囬 \\
\hline 3 & candy & 5.33 & Q 囬 \\
\hline 4 & didot & 6.66 & Q 囬 \\
\hline 5 & eka & 6.33 & $Q>$ 而 \\
\hline 6 & fitri & 7.66 & Q 囬 \\
\hline 7 & galuh & 7.33 & Q 而 \\
\hline 8 & heni & 5.66 & Q 囬 \\
\hline 9 & indah & 7.66 & Q 囬 \\
\hline 10 & jebri & 6 & Q 而 \\
\hline 11 & karin & 6.33 & Q 而 \\
\hline 12 & layli & 8.33 & Q 囬 \\
\hline 13 & maya & 6 & $Q>$ 面 \\
\hline 14 & nisa & 6.66 & $Q$ \\
\hline 15 & oni & 5.33 & Q 囬 \\
\hline 16 & pepi & 8 & Q 囬 \\
\hline 17 & ratna & 4.66 & Q 囬 \\
\hline 18 & sukma & 7.33 & $Q>$ 而 \\
\hline 19 & tina & 6 & Q 囬 \\
\hline 20 & ve & 7.66 & Q 囬 \\
\hline
\end{tabular}

Gambar 5. prototype penghitungan nilai V 
Hasil rangking ini didapatkan dari pengurutan nilai $\mathrm{V}$ dari terkecil ke terbesar. Perangkingan ini yang digunakan sebagai acuan posisi duduk siswa dalam kelas yang akan diimplementasikan pada pola posisi duduk yang ada dikelas ditunjukan pada Gambar 6 .

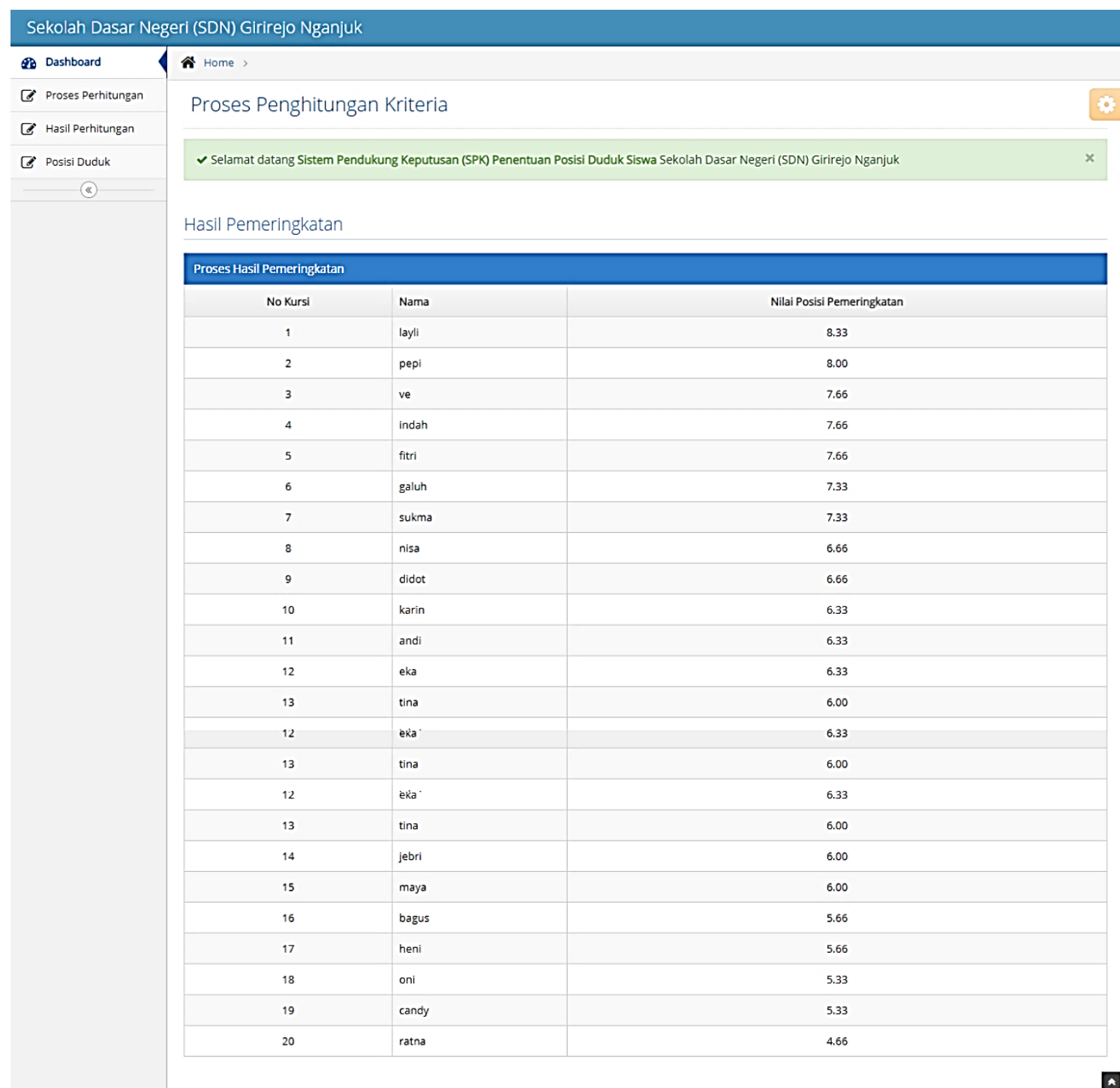

Gambar 6. prototype hasil rangking

Hasil dari penentuan alternatif posisi duduk berdasarkan kursi ditampilkan pada Gambar 7. 


\section{Posisi Duduk Alternatif}

$\checkmark$ Selamat datang Sistem Pendukung Keputusan (SPK) Penentuan Posisi Duduk Siswa Sekolah Dasar Negeri (SDN) Girirejo Nganjuk

Hasil Pemeringkatan

\begin{tabular}{|c|c|c|c|c|c|}
\hline \multicolumn{6}{|l|}{ Proses Hasil Pemeringkatan } \\
\hline No Kursi & $\max$ & \multicolumn{2}{|c|}{$\min$} & & \\
\hline No Kursi 1 & 8.33 & 8.15 & \multirow{3}{*}{\begin{tabular}{|l|}
8.33 \\
8.00 \\
\end{tabular}} & & \\
\hline No Kursi 2 & 8.15 & 7.96 & & & \\
\hline No Kursi 3 & 7.96 & 7.78 & & & \\
\hline No Kursi 4 & 7.78 & 7.6 & \multirow[t]{2}{*}{7.66} & \multirow[t]{2}{*}{7.66} & \multirow[t]{6}{*}{7.66} \\
\hline No Kursi 5 & 7.6 & 7.41 & & & \\
\hline No Kursi 6 & 7.41 & 7.23 & \multirow[t]{4}{*}{7.33} & \multirow[t]{4}{*}{7.33} & \\
\hline No Kursi 7 & 7.23 & 7.05 & & & \\
\hline No Kursi 8 & 7.05 & 6.86 & & & \\
\hline No Kursi 9 & 6.86 & 6.68 & & & \\
\hline No Kursi 10 & 6.68 & 6.5 & \begin{tabular}{|l|}
6.66 \\
\end{tabular} & \multicolumn{2}{|l|}{6.66} \\
\hline No Kursi 11 & 6.5 & 6.31 & \multirow[t]{2}{*}{6.33} & \multirow[t]{2}{*}{6.33} & \multirow[t]{2}{*}{6.33} \\
\hline No Kursi 12 & 6.31 & 6.13 & & & \\
\hline No Kursi 13 & 6.13 & 5.94 & \multirow{2}{*}{6.00} & \multirow[t]{2}{*}{6.00} & \multirow[t]{8}{*}{6.00} \\
\hline No Kursi 14 & 5.94 & 5.76 & & & \\
\hline No Kursi 15 & 5.76 & 5.58 & \multirow[t]{2}{*}{5.66} & \multirow[t]{2}{*}{5.66} & \\
\hline No Kursi 16 & 5.58 & 5.39 & & & \\
\hline No Kursi 17 & 5.39 & 5.21 & \multirow[t]{3}{*}{5.33} & \multirow[t]{4}{*}{5.33} & \\
\hline No Kursi 18 & 5.21 & 5.03 & & & \\
\hline No Kursi 19 & 5.03 & 4.84 & & & \\
\hline No Kursi 20 & \begin{tabular}{|l|} 
\\
\end{tabular} & 4.66 & 4.66 & & \\
\hline
\end{tabular}

Gambar 7. prototype hasil pencarian posisi alternative berdasar tempat duduk

Setelah dilakukan perhitungan pengujian pada nilai kriteria-kriteria pada SD Negeri Girirejo dengan menggunakan metode SAW diperoleh hasil: a) Kelebihan algoritma metode Simple Additive Weighting (SAW) dapat menghasilkan rangking untuk penentuan posisi duduk siswa. b) Kekurangan algoritma metode Simple Additive Weighting (SAW) memperhitungkan penentuan posisi alternatif berdasarkan tempat duduk.

Meskipun dengan menggunakan metode Simple Additive Weighting (SAW) sudah bisa menemukan rangking untuk menentukan posisi duduk siswa tapi setelah di kombinasikan dengan perhitungan selisih pencarian nilai tertinggi dan terendah untuk dicari posisi alternative namun hasilnya belum sesuai dengan yang diharapkan karena masih ada kursi yang masih kosong atau belum terpakai ke seluruh siswa yang ada dikelas. Perlu adanya evaluasi perbaikan lagi kedepan agar semua kursi dapat terisi oleh semua siswa dikelas.

\section{KESIMPULAN DAN SARAN}

\subsection{Kesimpulan}

Dalam penelitian ini sudah menghasilkan peringkat siswa untuk mendapatkan kursi, tetapi belum maksimal sesuai dengan yang direncanakan dikarenakan ketika objeknya digantikan dengan tempat duduk hasilmya masih ada kursi yang masih kosong tidak terisi oleh siswa, sehingga perlu dilakukan perbaikan kedepannya untuk bisa mencari alternative setiap kursi agar terisi oleh semua siswa dan dapat menghasilkan posisi alternative sehingga dapat membatu guru dalam memetakan posisi duduk siswanya yang ideal di dalam kelas. 


\subsection{Saran}

Adapun saran untuk memperbaiki hasil dan penyempurnaan sistem pendukung keputusan yang telah dibuat:

1. Sistem pendukung keputusan penentuaan posisi duduk siswa dalam kelas ini bisa menggunakan dengan metode-metode alternative lainnya yang dapat menghasilkan perangkingan, beberapa alternative seperti tempat duduk, meja dll.

2. Sistem pendukung keputusan penentuan posisi duduk siswa ini dapat ditambahkan kriteria lainnya seperti sudut pandang terhadap papan tulis dan guru, kemempuan mendengar, dll sehingga menghasilkan nilai yang lebih kompleks.

\section{DAFTAR PUSTAKA}

Ariyanto, Rudy. (2013). "Sistem Pendukung Keputusan Kelompok Untuk Seleksi Proposal Penelitian Hibah Bersaing Menggunakan Metode FAHP dan FMCDM (Studi Kasus: UPT P2M Politeknik Negeri Malang)". Tesis Program Studi S2 Ilmu Komputer Fakultas Matematika Dan Ilmu Pengetahuan Alam Universitas Gadjah Mada Yogyakarta” All GDSS PHB V.41 (Desember 2013).

Djamarah.dan Aswan. (2013). Strategi Belajar Mengajar. Jakarta. Rineka Cipta.

Gunawan (2007). Genius Learning Strategi. Jakarta: Gramedia Pustaka Utama.

Kusrini (2007). Konsep dan Aplikasi Sistem Pendukung Keputusan. Edisi I. Yogyakarta.Andi.

Kusumadewi. dkk. (2006). Fuzzy Multi-Atribut Decision Making (Fuzzy MADM). Yogyakarta: Graha Ilmu.

Madya. S. (2006) Teori dan Praktik Penelitian Tindakan (Action Research). Bandung. Alfabeta. 